\title{
Caso radiológico de desafío diagnóstico
}

Francisca Leiter $H^{\prime}$, Daniel Alvarez $G^{2}$, Pamela Bozzo $S^{2}$, Jorge Ortiz $V^{3}$, Cristián Varela $U^{3}$.

1. Médico Cirujano. Facultad de Medicina, Universidad de los Andes. Santiago-Chile. francisca.leiter@gmail.com

2. Residente de Postgrado en Radiología. Facultad de Medicina, Universidad de los Andes. Santiago-Chile.

3. Médico Radiólogo. Servicio de Imaginología, Clínica Dávila. Santiago-Chile.

\section{Caso Clínico}

Paciente de sexo femenino de 35 años de edad, sin antecedentes mórbidos de importancia. Puérpera de 5 meses de un RNT de 38+5 semanas, sano. Parto vaginal espontáneo, sin incidentes.

Consulta en forma ambulatoria por cuadro de 4 semanas de evolución caracterizado por astenia, sudoración excesiva, palpitaciones y temblor de predominio en las extremidades inferiores.

En la evaluación al ingreso se encuentra normotensa (PA: 130/70 mmHg), taquicárdica (FC: $120 \mathrm{lpm}$ ) y afebril (To: $36,6^{\circ} \mathrm{C}$ ), presentando un aspecto sudoroso. El examen físico segmentario revela aumento de volumen cervical anterior homogeneo e indoloro, probablemente en relación a la glándula tiroides. Resto del examen físico sin hallazgos.

Dentro de los exámenes de laboratorio solicitados destaca una TSH $<0.015 \mathrm{UUI} / \mathrm{ml}$ y una T4l $>6.99 \mathrm{ng} /$ dL. Se complementa el estudio con ecografía de tiroides (Figuras 1a, 1b, y 2).

\section{¿Cuál es su diagnóstico?}

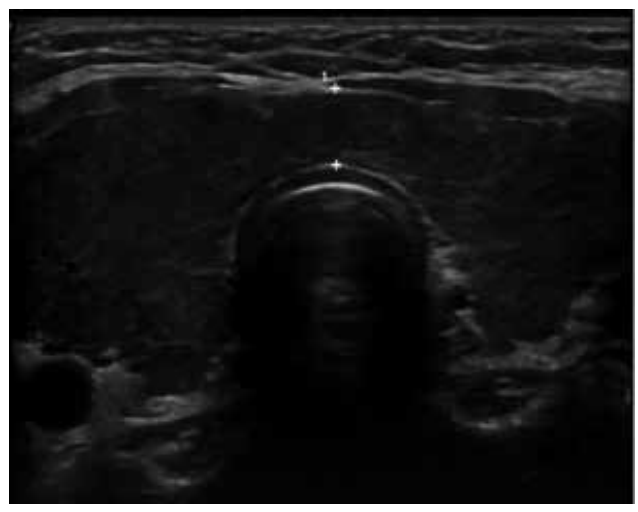

Figura $1 a$.

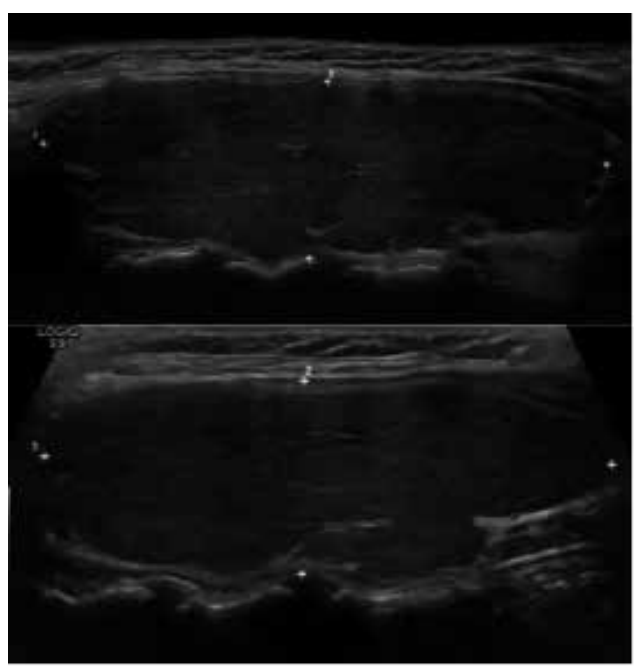

Figura $1 b$.

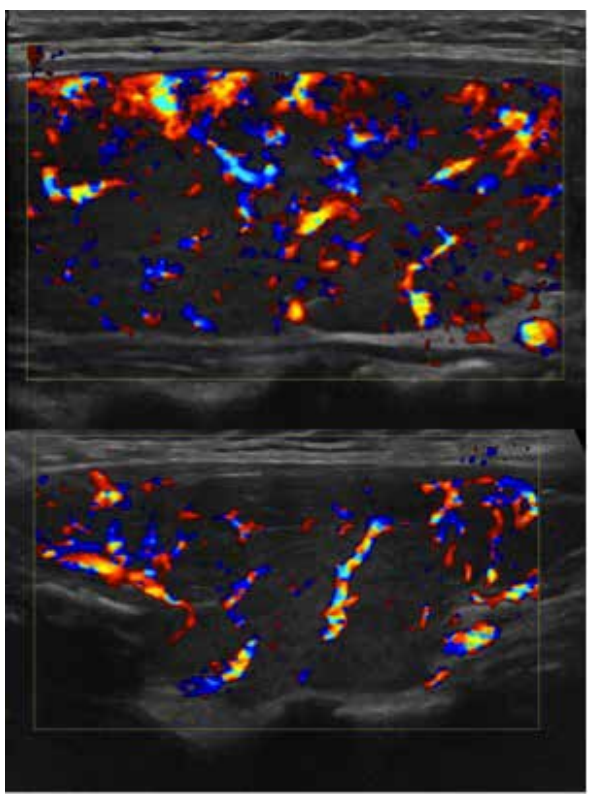

Figura 2. 


\section{Resultado caso radiológico de desafío diagnóstico}

\section{Dres. Francisca Leiter $H^{\prime}$, Daniel Alvarez $G^{2}$, Pamela Bozzo $S^{2}$, Jorge Ortiz $V^{3}$, Cristián Varela $U^{3}$.}

1. Médico Cirujano. Facultad de Medicina, Universidad de los Andes. Santiago-Chile. francisca.leiter@gmail.com

2. Residente de Postgrado en Radiología. Facultad de Medicina, Universidad de los Andes. Santiago-Chile.

3. Médico Radiólogo. Servicio de Imaginología, Clínica Dávila. Santiago-Chile.

\section{Diagnóstico}

Tiroiditis post parto, probablemente Enfermedad de Graves.

\section{Hallazgos}

El estudio ecográfico en escala de grises muestra la glándula tiroides globalmente aumentada de tamaño, con ecoestructura heterogénea de aspecto pseudonodular. Además, presenta leve disminución difusa anormal de su ecogenicidad (Figura 1a y 1b).

Al estudio Doppler - Color, se observa un marcado aumento difuso de la vascularización glandular (Figura 2).

En modo Doppler - Espectral, existe aumento de la frecuencia cardíaca en rango de taquicardia. En modo Doppler - espectral, el estudio dirigido de la arteria tiroídea inferior derecha desmuestra marcado aumento de la velocidad de peak sistólico la que supera los $100 \mathrm{~cm} / \mathrm{s}$ (Figura 3).

A la exploración del resto de la región cervical, se identifican numerosos y pequeños linfonodos de aspecto inespecífico en el grupo $\mathrm{VI}$, probablemente reactivos, que miden hasta $6 \mathrm{~mm}$ (Figura 4).

Dentro de los estudios complementarios, se realiza determinación de anticuerpos donde destacan: anticuerpos Anti-Tiroglobulina de $95.5 \mathrm{Ul} / \mathrm{mL}$, anticuerpos

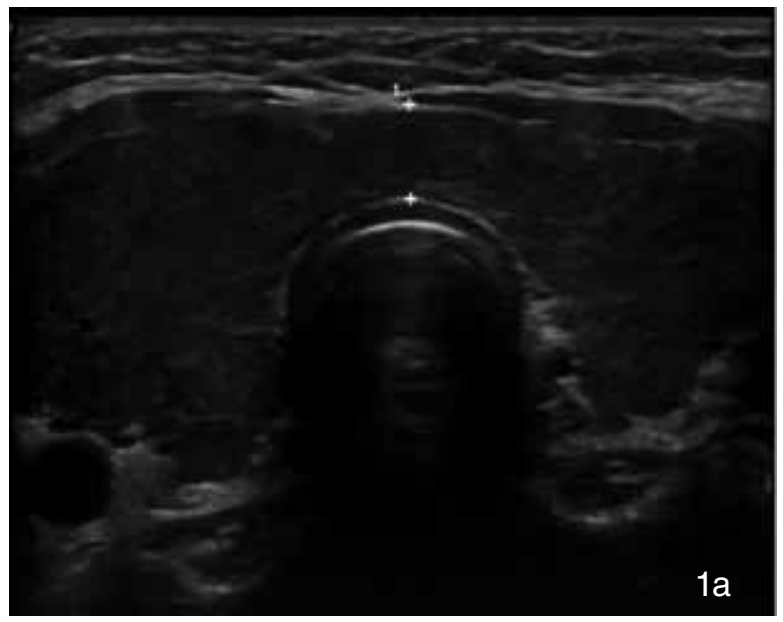

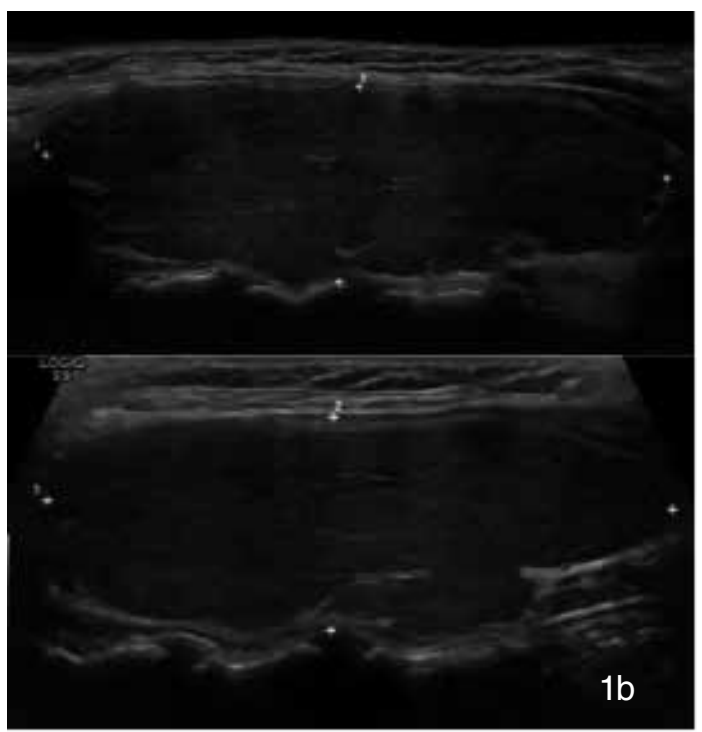

Figura 1a. Imagen en modo $B$, obtenida con transductor lineal de alta resolución. Corte axial de la tiroides a nivel del istmo. Se observa aumento de volumen difuso y disminución de la ecogenicidad de la glándula, sin identificar formaciones nodulares. Figura 1b. Cortes sagitales.

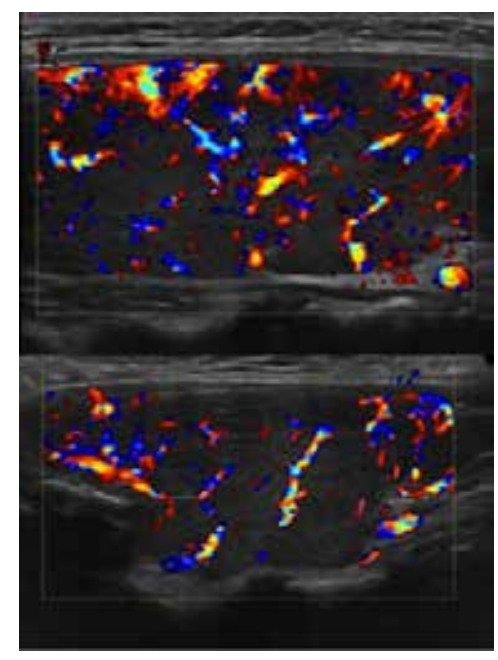

Figura 2. Imágenes en modo Doppler-color. Existe marcado aumento de la vascularización glandular, más acentuada en el lóbulo derecho. 


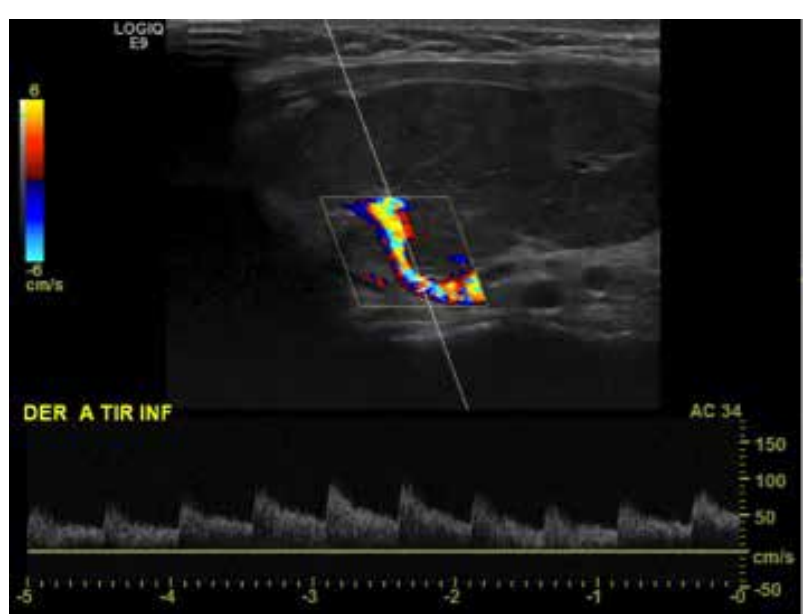

Figura 3. Imagen en modo Doppler - Espectral. El estudio dirigido de la arteria tiroidea inferior derecha demuestra el aumento de la velocidad de peak sistólico, la que supera los $100 \mathrm{~cm} / \mathrm{s}$.

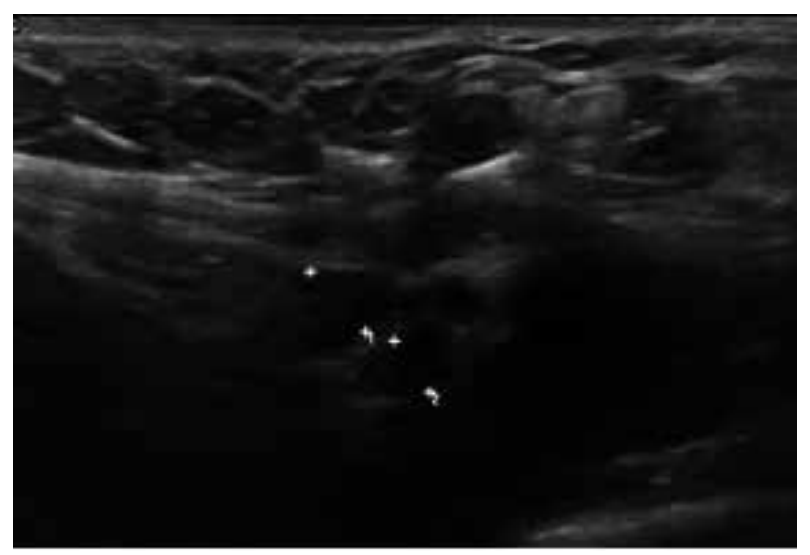

Figura 4. Imagen en modo $B$, obtenida con transductor lineal de alta resolución. Se identifican linfonodos de hasta $6 \mathrm{~mm}$ de diámetro, que impresionan reactivos.

Anti-Peroxidasa de $45 \mathrm{UI} / \mathrm{mL}$ y anticuerpos AntiReceptor de TSH de $19.49 \mathrm{UI} / \mathrm{mL}$. Estos elementos permiten establecer el diagnóstico de Enfermedad de Graves postparto.

\section{Conclusión}

La enfermedad tiroídea autoinmune del postparto corresponde a una disfunción de la glándula tiroides durante el período postnatal, en mujeres sin antecedentes previos de patología tiroídea ${ }^{1}$. Su prevalencia es de aproximadamente $5-10 \%$, presentándose en $50-60 \%$ de los casos como una tirotoxicosis transitoria destructiva, también conocida como Tiroiditis postparto (TPP) $)^{2}$.

La TPP es una tiroiditis linfocitaria subaguda silente de etiopatogenia autoinmunitaria, que se presenta durante el primer año posparto en mujeres con susceptibilidad genética. Clásicamente cursa con una fase hipertiroidea inicial, durante los primeros tres meses postparto, que puede ir seguida de una fase hipotiroidea entre el tercer y sexto mes postparto. El $40 \%$ a $70 \%$ de las pacientes con TPP presenta bocio difuso, principalmente en la fase de hipotiroidismo ${ }^{3}$.

Aunque la fase hipertiroidea de la TPP es generalmente oligosintomática, el principal diagnóstico diferencial a considerar es la Enfermedad de Graves postparto, ya que la evolución y tratamiento de ambas patologías es diferente.

La Enfermedad de Graves del postparto corresponde a un trastorno autoinmune caracterizado por la unión de anticuerpos contra el receptor de tirotropina (TRAb) de las células foliculares, lo que estimula la síntesis y secreción de hormonas tiroídeas además de un aumento de volúmen difuso de la glándula ${ }^{4}$. Su prevalencia, considerando las formas persistente y transitoria, alcanza el $11 \%$ de las disfunciones tiroideas del postparto y afecta al $0.54 \%$ de las mujeres en el período postnatal ${ }^{2}$. Generalmente se presenta entre el cuarto y sexto mes postnatal, destacando clínicamente la presencia de bocio difuso y tirotoxicosis, pudiendo o no asociarse a oftalmopatía y orbitopatía infiltrativa ${ }^{3,4}$.

La diferenciación entre ambas patologías se basa principalmente en los exámenes de laboratorio, siendo la determinación de anticuerpos contra el receptor de tirotropina (TRAb) la herramienta más especifica para identificar la Enfermedad de Graves².

Desde el punto de vista radiológico, existen elementos ecográficos que contribuyen a la discriminación entre ambas entidades. Ecograficamente, tanto en la Enfermedad de Graves como en la tiroiditis postparto existe un aumento de volúmen global de la glándula, la que presenta ecotextura heterogenea y ecogenicidad disminuida en grados variables ${ }^{4}$. Las modalidades Doppler - Color y Doppler - Espectral son especialmente útiles para distinguir entre las tirotoxicosis causadas por sobreproducción hormonal y aquellas secundarias a destrucción glandular.

En la etapa precoz de la Enfermedad de Graves, el estudio Doppler - Color muestra un marcado aumento del flujo sanguíneo glandular, patrón ecográfico conocido como "infierno tiroideo", que en la mayoría de los casos representa un aumento del flujo sanguíneo tiroídeo mayor al 4\%. En las tiroiditis postparto, en cambio, el aumento del flujo sanguíneo tiroídeo es siempre menor a $4 \%^{2-4,5}$.

Dentro de los elementos ecográficos de mayor utilidad para el diagnóstico de Enfermedad de Graves, el estudio en modalidad Doppler - Espectral muestra un aumento de la velocidad de peak sistólico en las arterias intratiroideas y peritiroideas de mediano calibre. Una velocidad de peak sistólico en la arteria tiroídea inferior por sobre $60 \mathrm{~cm} / \mathrm{seg}$ tiene especificidad reportada del $100 \%$ y una sensibilidad del $80 \%$ 
para diferenciar la Enfermedad de Graves de otras causas de bocio tóxico difuso ${ }^{4-6,7}$.

En resúmen, la ecografía tiroídea constituye una herramienta de gran utilidad para diferenciar tirotoxicosis causadas por sobreproducción hormonal de aquellas tiroiditis donde existe destrucción glandular ${ }^{4}$. Tanto el modo B como las modalidades Doppler Color y Doppler - Espectral, entregan información que sugieren el diagnóstico de Enfermedad de Graves con alta sensibilidad y especificidad, si bien cabe destacar que el diagnóstico de esta patología se configura con elementos clínicos, serológicos e imaginológicos, todos los cuales deben ser valorados por un subespecialista del área endocrinológica.

\section{Bibliografía}

1. Amino N., Tada H., Hidaka Y. Postpartum Autoinmune Thyroid Syndrome: A Model of Aggravation of Autoinmune Disease. Thyroid, 199; 9(7): 705-713.

2. Ide A., Amino N., Kang S., Yoshioka W., Kudo T., Nishihara E., et al. Differentiation of Postpartum Graves' Thyrotoxicosis from Postpartum Destructive Thyrotoxi- cosis Using Antithyrotropin Receptor Antibodies and Thyroid Blood Flow. Akane Ide et al. Thyroid, 2014; 24(6): 1027-1031.

3. A.M. Lucas. Tiroiditis posparto. Endocrinol Nutr 2004; 51(5): 303-307.

4. Biatta Sholosh MD., Amir A. Borhani MD. Thyroid Ultrasound Part 1: Technique and Diffuse disease. Radiologic Clinics 2011; 49(3): 391- 416.

5. Ralls PW., Mayekawa DS., Lee KP,. et al. Color-flow Doppler sonography in Graves disease: "thyroid inferno". AJR Am J Roentgenol 1988; 150: 781- 784.

6. Saleh A., Cohnen M., Furst G., et al. Differential diagnosis of hyperthyroidism: Doppler sonographic quantification of thyroid blood flow distinguishes between Graves' disease and diffuse toxic goiter. Exp Clin Endocrinol Diabetes 2002; 110: 32-36.

7. Sayid Shafi Zuhur,I Alper O "zel,II Selvinaz Velet,I Mehmet Sait Bug dacı, III Esra C il,I Yu" ksel Altuntasl. Is the measurement of inferior thyroid artery blood flow velocity by color-flow Doppler ultrasonography useful for differential diagnosis between gestational transient thyrotoxicosis and Graves' disease? A prospective study. Clinics 2012; 67(2): 125-129.

Leiter F., et al. Tiroiditis post parto, probablemente Enfermedad de Graves. Rev Chil Radiol 2017; 23(1): 30-33. Correspondencia: Francica Leiter / francisca.leiter@gmail.com

Trabajo recibido el 24 de agosto de 2016. Aceptado para publicación el 30 de septiembre de 2016.

Trabajo realizado en el Servicios de Imaginología de la Clínica Dávila, Chile. 2015. 